\title{
Introduction: Beijing+20 - Where now for Gender Equality?
}

\author{
Andrea Cornwall and Jenny Edwards
}

\begin{abstract}
The Beijing Declaration and Platform for Action (BPfA) is 20 years old. This introduction revisits the promises of the Beijing conference and reflects on how these have materialised amidst broader changes in the political economy of development. Most significant is the shift in the role of the state, with the entry of new development actors into the development policy and practice arena and growing private sector engagement. One consequence of this is that in the enthusiasm of corporate campaigns promoting women and girls as self-actualising individuals who can lift their communities out of poverty, effective implementation of progressive policies is getting lost. An important legacy of Beijing is the buzz it created within women's organising and the opportunities offered for the creation of transnational and local alliances. In conclusion we underline the hugely important part the energy of women's organisations continues to play in achieving positive and sustainable change.
\end{abstract}

The Beijing Declaration and Platform for Action (BPfA), celebrated by feminist activists around the world as a triumph for women's rights, is 20 years old. The world that it once described has changed profoundly in some respects, and yet in others remains surprisingly similar. This IDS Bulletin reflects on those changes and continuities, tracing the trajectories of the Beijing conference in different policy arenas, national settings and domains of practice. In this introduction, we reflect on what the BPfA has offered feminist activists. We examine how some of the frames of reference used in the BPfA map onto the terrain of discourse of contemporary global development policy. And we explore areas yet unmarked at the time that have become important arenas for feminist contestation and creativity.

\section{The Beijing Platform for Action}

The Fourth World Conference on Women set out an ambitious vision for change. It elicited commitments for achieving gender equality from 189 UN member states. The BPfA identified 12 critical areas of concern, and set strategic objectives and actions. It built on the 1979 UN Convention on the Elimination of All Forms of Discrimination against Women (CEDAW) and a series of landmark conferences - Mexico (1975), Nairobi (1985), Vienna (1993), Cairo (1994) and Copenhagen (1995) - to assert women's rights as human rights, and insist that global governance take seriously obligations to gender equality and to ending discrimination against women.

As Rosalind Eyben in this IDS Bulletin reflects, the mythology surrounding Beijing is arguably more influential than the official agenda for action agreed at the conference. Its name now conjures up a wealth of meanings, encompassing women's activism, rights, equality and empowerment. The excitement around the conference fed a new era of women's mobilisation; it came to be symbolic of a groundswell of women working together across borders to bring about change for the world's women - and men. Far less prominent in representations of Beijing are the tensions, disagreements and disappointments that were also part of the scene. Rather, Beijing comes to symbolise a rallying call for feminist activists, used to mark out certain lines of argument or kinds of actors, as Takyiwaa Manuh and Nana Akua Anyidoho in this IDS Bulletin note for Ghana.

In some respects, Beijing's traction has been precisely through this symbolism, whether or not what emerged was actually implemented. Yet as Suzette Mitchell reminds us (this IDS Bulletin), the effects of Beijing went well beyond framing. It served as a space for coalitions, alliances and connections, 
and for creating networks of solidarity with a global constellation of advocates and activists. She reflects:

Participating actively in the Beijing conference and NGO Forum in the knowledge that it was the largest gathering of (mostly) women ever staged, as a part of a global women's movement that interacts on the UN stage, has shaped me as the feminist development worker that I am. It has influenced the way I analyse issues as a feminist, how I organise on ideas as an activist, and the topics on which I choose to work. For me, the Beijing process was a watershed.

The BPfA speaks, in Paragraph 17, of the importance of fostering

a new era of international cooperation among Governments and peoples based on a spirit of partnership, an equitable, international social and economic environment, and a radical transformation of the relationship between women and men to one of full and equal partnership [that] will enable the world to meet the challenges of the twenty-first century.

The BPfA reflects on aspects of the current conjuncture at that time: the end of the cold war, the reduced threat of global armed conflict, improved international relations, and prospects for peace and security. It acknowledged that structural adjustment had caused poverty, although only as far as to say that it was 'poorly implemented'. It recognised the wave of democratisation opening up the political process, although not as yet with much gain for women's political representation. And it registered the impact of rapid economic change producing rising unemployment and underemployment 'with a particular impact on women'.

Looking at the BPfA's 12 areas of concern from the vantage point of the present, what has changed, what has stayed the same and what wasn't even on the agenda then? The 12 areas are: women and poverty; education and the training of women; women and health; violence against women; women and armed conflict; women and the economy; women in power and decision-making; institutional mechanisms for the advancement of women; human rights of women; women and media; women and the environment; the girl child.

On the face of it, it would seem that little has shifted substantively in the framing of international policy discourse on women's rights and gender equality in terms of issues, even if there has been some reconfiguration of the ways in which these themes are now presented and prioritised in policy arenas (see contributions in this IDS Bulletin by Woodroffe and Hunt). All 12 areas remain significant foci, arguably attenuated in their scope by the deflective impact of the reductionism of the Millennium Development Goals (MDGs). Some - such as media and environment - have become more significant. Others have struggled for resources and attention, or have been subject to ideological contests that have further diminished women's rights.

Yet a closer look at the language and framing of the BPfA reveals one powerfully salient contrast with today. The discourse of Beijing was that of the heyday of social development, riding on the wave of the string of post-cold war UN conferences that opened up an optimistic new phase in intergovernmental collaboration. Paragraph 5 notes:

The success of the Platform for Action will require a strong commitment on the part of governments, international organizations and institutions at all levels. It will also require adequate mobilization of resources at the national and international levels as well as new and additional resources to the developing countries from all available funding mechanisms, including multilateral, bilateral and private sources for the advancement of women; financial resources to strengthen the capacity of national, subregional, regional and international institutions.

Back in 1995, the state was still seen as the most important of development actors, the focus for feminist advocacy. Today's development policy arenas are permeated with the settlements that the development industry has made with corporate power. What we see is the advance within them of the language of business, along with an emphasis on enterprise and the centrality of the private sector as the engine of change. The UK government is a good example, having been chastised recently by its own independent watchdog, the Independent Commission for Aid Impact (ICAI) for a lack of clarity about how support for the private sector is to benefit the poor (Anderson 2015). Alongside this, there have been major changes in international relations that have redrawn the map of geopolitical tensions in ways that are highly significant for the politics of gender and women's empowerment, as Navtej Purewal's contribution in this IDS Bulletin reminds us powerfully. The emerging geopolitics that 
have come to form the backdrop to development and security policy lay bare the dissonance between this actually existing present and the one that the BPfA evoked.

\section{Work, voice and body politics}

What of the BPfA's substantive areas of focus? What progress has there been? Contributors to this IDS Bulletin chart the development of policies and practice in a constellation of different settings around the world, drawing out some of the obstacles to progress and gains for women's rights. In what follows, we draw on these contributions and on debates about the contribution of Beijing to the field of gender equality and women's empowerment. We explore three areas that have become a major focus for attention in the intervening two decades: creating more opportunities for women to earn a living and exercise economic autonomy; enhancing women's political representation and enabling women to have more of a say in the decisions that affect their lives; and affirming women's rights to have control over their own bodies and a sexuality of their own choosing.

\subsection{Work}

The very 'accelerated economic growth' that was recognised in Paragraph 14 of the BPfA as 'aggravate[ing] social inequality and marginalization' has come over the intervening decades to preside at the core of mainstream international development policy. Inequality may be a word that is being heard in all kinds of places at the moment, including in the heartlands of international development. But orthodoxies about economic growth as a driver of positive change retain their hegemony. Neoliberalism had been swift and expansive in its colonisation of women's economic empowerment over this period. A key difference between the world that the BPfA addressed in 1995 and today's realities is the panoply of new development actors emerging over the last two decades, whose role was barely anticipated in the BPfA. Indeed, one of the most striking contrasts is the disappearing role of the state, eclipsed by the rise and influence of non-governmental and private sector actors.

Concerns raised in the BPfA have become an everpresent reality for millions of the world's women - and men and trans and intersex people - as neoliberalism has bitten ever harder. Paragraph 19, for example, well describes the very conditions of work that have accompanied women's entry into the labour market in larger numbers over the last two decades:
Women often have no choice but to take employment that lacks long-term job security or involves dangerous working conditions, to work in unprotected home-based production or to be unemployed. Many women enter the labour market in under-remunerated and undervalued jobs, seeking to improve their household income; others decide to migrate for the same purpose. Without any reduction in their other responsibilities, this has increased the total burden of work for women.

As demonstrated by UN Women in Progress of the World's Women 2015-16, notwithstanding the significance for women's economic autonomy of the widening of opportunities to enter the labour market, lack of decent work for women is still a major women's rights issue in most countries. As UN Women report, 83 per cent of domestic workers worldwide are women and almost half of them are not entitled to the minimum wage (UN Women 2015). Many of the new economic opportunities that have arisen in the last two decades offer women fragile labour rights, low pay and arduous, difficult and even dangerous working conditions. While evidence points to the extent to which women can find empowerment even under these conditions, and especially to the significance of a regular, independent income for women's empowerment (Kabeer 2012), it is also evident that much needs to be done to improve women's access to better paid, better protected, more skilled employment and address the gender pay gap and gender segregation in labour markets (UN Women 2015). Paola Termine and Monika Percic's contribution to this IDS Bulletin offers a critical analysis of the conceptualisation of women's empowerment through employment and decent work, as situated in a trajectory from antecedents of Beijing through to the MDGs and the post-2015 development agenda.

As women have entered work in greater number, changes in the domestic alignment of responsibilities remains sluggish, even in advanced economies (Vinkenburg, this IDS Bulletin). Looking back at the BPfA, Paragraph 27 registers an increase in women's economic engagement leading to an impetus for change in the domestic division of labour:

The boundaries of the gender division of labour between productive and reproductive roles are gradually being crossed as women have started to enter formerly male-dominated areas of work and men have started to accept greater responsibility for domestic tasks, including 
childcare. However, changes in women's roles have been greater and much more rapid than changes in men's roles. In many countries, the differences between women's and men's achievements and activities are still not recognized as the consequences of socially constructed gender roles rather than immutable biological differences.

Twenty years later, what has come to be termed the 'care economy' has become ever more visible as a development issue, not least because of the disappearing role of the state in the provision of social goods and the increasing privatisation of the social - including, as Ana-Laura Rodríguez Gustá and Nancy Madera note in their contribution to this IDS Bulletin, the privatisation of city space. This has been accompanied by an increasing focus on the self-actualising individual, shifting the locus of agency and responsibility away from collective actors - including the state - to women themselves, harnessing 'gender myths' (Cornwall, Harrison and Whitehead 2007), including that women are naturally more inclined to spend their earnings taking care of their families and mitigating poverty at the household level. Navtej Purewal's critical examination of the discourse on girls' education highlights the problematic aspects of this shift in emphasis; as Sarah Bradshaw notes of the disaster risk reduction agenda, women are instrumentalised rather than being served by development.

Feminists have done significant work on the design of social protection policies, gender budgeting and integrating human rights principles into macroeconomic policy (Balakrishnan and Elson 2011); and there are some inspiring examples where policy and practice has bucked the overall trend, including in contexts where women's budgets and feminist cash transfer policies have strengthened state capacity to deliver on accountability to women as citizens (Sholkamy 2011). And yet neoliberal economic policies have had a disastrous effect on social safety nets, further deepening the economic marginalisation of vulnerable groups.

\subsection{Voice}

The diminished sphere of statutory intervention and provision in the wake of globalisation and privatisation makes the kind of world envisioned in the BPfA a very different one to the one in which most of us now live. This has significant implications for the capacity of national governments to deliver on women's rights using the kinds of mechanisms envisaged in the era of Beijing. Despite the focus in the BPfA on securing broad-based participation of women in shaping the decisions that affect their lives, women's political empowerment has been effectively reduced to a mechanistic response geared at populating parliaments with women. Opportunities for feminist political apprenticeship remain limited, and it is clear that women do not always act in the interests of other women, especially when privilege kicks in and frames allegiances and alliances (Tadros, this IDS Bulletin). With the emphasis on numerical targets, other dimensions of difference have slipped out of view. The BPfA notes, for example, in Paragraph 31:

Many women face particular barriers because of various diverse factors in addition to their gender. Often these diverse factors isolate or marginalize such women. They are, inter alia, denied their human rights, they lack access or are denied access to education and vocational training, employment, housing and economic self-sufficiency and they are excluded from decision-making processes. Such women are often denied the opportunity to contribute to their communities as part of the mainstream.

There is only a contingent connection between women's presence in these arenas and voice on gender equality issues; descriptive representation meets its limits as gender comes to intersect with other dimensions of difference, most notably class and race. And there is less still in this agenda about building a political constituency for gender equality in a way that traverses and disrupts essentialised uses of the gender binary - including tired assumptions about women's virtuousness and willingness to act for and in solidarity with other women. Challenging these kinds of simplifications becomes more difficult still in an environment in which gender stereotypes and sexualised representations of women politicians and political candidates dominate the way in which the media engages with women's political representation. There remains a huge amount of work to do in this area.

\subsection{Body politics}

This is where the BPfA made significant advances for women's sexual and reproductive rights. The language achieved in Paragraph 96 - for all its heteronormativity - was an unparalleled gain for women's rights, building on advances made at the World Conference on Human Rights in Vienna in 1993 and the International Conference on Population and Development in Cairo in 1994: 
The human rights of women include their right to have control over and decide freely and responsibly on matters related to their sexuality, including sexual and reproductive health, free of coercion, discrimination and violence. Equal relationships between women and men in matters of sexual relations and reproduction, including full respect for the integrity of the person, require mutual respect, consent and shared responsibility for sexual behaviour and its consequences.

This language has become difficult to protect. Religious conservative interests have become both more vocal, with rising intolerance towards sexual diversity coupled with further entrenchment of the denial of women's reproductive rights. Development's engagement with sexuality has until very recently been primarily concerned with danger, disease and harm, rather than the positive enjoyment of our bodies, sexualities and right to a sexuality of our own choosing (Jolly, Cornwall and Hawkins 2013). Nyx McLean and Tiffany Kagure Mugo (this IDS Bulletin) demonstrate the importance of a positive approach to sexuality, and celebrate the significance of organising on and off-line for women's sexual rights. They note how the internet opens up spaces for counter-publics to emerge and build constituencies around issues of sexuality. Virtual spaces, they suggest, can offer safer arenas for people to assert their own interpretations of identities and interests. They also provide a way to connect and mobilise those who would otherwise remain isolated as well as marginalised.

\section{Institutional responses: moving forward on Beijing}

At an institutional level, it is important to recognise progress in developing and domesticating the normative framework for addressing women's human rights in practice. The CEDAW Committee has made a number of steps forward, including championing the adoption of an optional protocol to strengthen CEDAW in 2000. The Protocol to the African Charter on Human and Peoples' Rights on the Rights of Women in Africa was adopted in 2003. These gains are most visible in the area of peace and security, following landmark Resolution 1325 and subsequent Security Council resolutions aimed at ending sexual violence in conflict and engaging women to participate in peace processes. More than 50 countries now have National Action Plans on women, peace and security. Regional resolutions have also been adopted, and reforms to national laws and policies on women's rights, especially in the area of violence.
Yet for all these gains, there remains a yawning gap between the promise of protocols and the realities of the lives of millions of women and girls the world over. In the 20 years that have passed, it has become evident that states were happier to sign up in lip service to its promises than to commit resources and policy space to realising their obligations. Implementation remains a persistent challenge. Many articles in this IDS Bulletin concern this long, slow process of turning the commitments of Beijing into real gains for women's rights and the implications for turning subsequent commitments into action. For all the 'spirit of determination, hope, cooperation and solidarity' of Article 7 of the preamble to the BPfA, getting anything done within the UN itself has been an uphill struggle, as Suzette Mitchell makes clear. And yet feminist bureaucrats have been able to secure gains through subversively negotiating corridors of power, working with change-makers outside as well as inside their organisations to create the conditions for the uptake of commitments (Eyben and Turquet 2013). Rosalind Eyben highlights the significance of those gains, urging us not to overlook the role of those within the bureaucracy in securing small wins that open the way for others to pursue agendas for change, in difficult environments with governments not following through on promises and constrained resources. One of the areas for substantial critical reflection when it comes to implementation challenges has been the effectiveness - or not - of what came to be called 'gender mainstreaming' as a vehicle for institutional change. A number of contributors to this IDS Bulletin (Rao, Kelleher and Miller; Milward, Mukhopadhyay and Wong; Stock; Tadros) address the associated challenges.

Coming only a handful of years after Beijing, the MDGs absorbed significant energies and directed the efforts of international development institutions towards a set of narrowly defined, measurable, goals. The consequences were to reduce the broadbased agenda set in Beijing. The MDGs addressed a diminished part of the BPfA areas of concern in relation to poverty, education, (maternal) health, women in power and decision-making, and women and the environment. In some areas, gains were made that included securing new commitments from the UN - such as Resolution 1325 and associated women, peace and security resolutions. In others, we have seen if anything a retrogressive environment emerging in which geopolitical and ideological considerations have come to the fore, notably around women's reproductive and sexual rights. 
The post-2015 discussions offer little succour for those concerned to see the Sustainable Development Goals (SDGs) advance the goals set out in Beijing. The standalone goal on 'Gender Equality and the Empowerment of Women and Girls' represents the outcome of advocacy to ensure women's rights are not left out of the frame. But the devil will be in the detail of what counts and what gets counted. One of the biggest challenges for the SDGs, as Sarah Bradshaw argues in this IDS Bulletin, is to move from rhetoric to tangible, realisable actions that are able to address social processes - and the challenge of transforming societies - rather than a narrow set of measurable outcomes. As Anke Stock (this IDS Bulletin) notes, looking at the arena of sustainable development and climate change, 'a gender lens highlights all too clearly how the marrying of the sustainable and development agendas is perhaps only a marriage of convenience'. It remains to be seen whether the SDGs can serve as a vehicle for a more transformative gender agenda.

\section{Addressing inequality and discrimination}

Looking back at 1995, for all that has changed, much of the inequality and discrimination that was such a focus for feminist activism and advocacy at Beijing remains alive and kicking. And for all the steps taken to promote and support women's rights, we have seen backlash and retrogression damage their prospects. Arguments have been mounted using 'culture', 'tradition' and 'religion' to resist progress on women's rights and push back on human rights commitments. The recourse to the domain of the economic has left little scope for effective engagement with a broader agenda for change that also addresses social, cultural and more broadly political concerns. There is in all this - and despite the revival of talk about inequality - little substantive engagement of the development industry with the structural inequalities that sustain the status quo.

Meanwhile, social and political energy to address these persistent inequities and inequalities lies elsewhere. Around the world, new forms of feminism have emerged bringing a new wave of mobilisation that is redefining responses to the current conjuncture. From feminist engagement through popular movements organising around austerity to the creative use of digital and social media for activism on women's rights, there has been a flowering of creativity as women have 'taken back the tech' and made use of online spaces to press demands and reframe debates. ${ }^{1}$ There are points of coincidence and prospects for convergence that can bring these worlds into intersection with formal policy spaces. Evidence points to the significance of women's autonomous organising and activism in the promotion of women's rights, not just in framing demands but also in securing gains for gender justice (Htun and Weldon 2010; Cornwall 2014). And yet, for all the rhetoric about 'investing in women', funds for the feminist organising that does make a difference remain scarce. As a recent UN Women Expert Group Meeting report on progress since the BPfA notes,

Advances in the enjoyment of women's rights are most likely to occur when social movements are involved in demanding change, and when coalitions and alliances supporting gender equality are formed. Alliances are needed across social sectors, between generations, and also across national borders... To this end, women's rights organisations and movements require secure funding and resources to be able to function effectively and yet there is a lack of dedicated resources for these groups. The implementation of the Beijing Platform will continue to be limited without dedicated funding... (UN Women 2014: 7).

A call to support women's organisations to claim rights and shape policy agendas at all levels is one of the ten priorities for public action of Progress of the World's Women 2015/16 (UN Women 2015).

\section{Re-animating the gender agenda}

So what are the ways forward that can re-animate some of the radical potential of gender equality and women's empowerment in today's world? Our contributors identify a number of pathways. Several draw attention to the potential of more unruly forms of feminist engagement that seek out and make use of spaces outside the institutions of aid and development, carving out the possibilities for enlisting new constituencies and generating alternative discourses and practices. Asking about the relevance of square brackets in UN negotiating spaces to women on the ground, Rosalind Eyben (this IDS Bulletin) argues for the need to redirect our gaze to dynamic spaces where things are happening completely outside the ambit of governmental spaces. Others see connections lacking and needing to be made and remade between grassroots movements on the ground and the spaces of representation in which international policies are debated. Transnational and virtual movement building practices offer an exciting potential arena for action, especially around some of the most entrenched areas of contestation - such as sexual rights, as in McLean and Mugo's contribution to this IDS Bulletin. 
A second arena is that of knowledge. Kirsty Milward, Maitrayee Mukhopadhay and Franz Wong (this IDS Bulletin) call for the reinvention of strategies of engagement that are able to expose the workings of power that make us complicit with harmful and inappropriate ways of doing development, arguing that

Future feminist engagement has to be both about the politics of refusal and of knowledge production that is subversive which 'defy reinscription in the mainstream' (Mukhopadhyay 2014: 356).

Given the extent to which feminist knowledge has been selectively appropriated to serve neoliberal development agendas, this poses a number of challenges - especially in terms of the sources of funding for transgressive and subversive knowledge production. Yet the unruly freedoms of the internet, open source publishing, blogging and social media offers media through which dominant discourses can be vigorously contested, and spaces created that defy the stale stereotypes and essentialisms that are so much part of the mainstream of development discourse. It is in these spaces that the victim-heroine binary that is so pervasive within the representations of women and girls by international NGOs, corporations and governments alike can be contested, and replaced by the more nuanced realities of women, men, girls, boys, intersex and trans people (Koffman and Gill 2014). Feminist funders like Mama Cash, whose inspirational work is captured in the article written by Zohra Moosa, have a vital role to play here, in fostering capacity and channelling funding to feminist groups and organisations, seeding their capacity to make change happen through creative communications.

Lastly, feminist visions of empowerment that predate the Beijing conference and that span decades of engaging the political and the personal need to be reinvigorated. Critics have highlighted the extent to which the world of international development institutions has become a stagnant, sterile space characterised by the enthusiastic promotion of the girl child and woman as entrepreneur, backed by corporates and international NGOs. It's time to reverse that equation, to learn lessons from the successes achieved by mobilising collectively, from processes that generate critical consciousness and from the world-changing work that is going on to frame and act on alternatives. For this, we need to look outside the development industry to those places where a flowering of resistance and creativity has led to the emergence of alternative democratic and economic possibilities. The road map to a different possible world that Beijing offered us is as relevant today as in 1995. It's one that could do with some updating and some revision, but the vision of a more equal, fairer, safer world is one to continue to aspire to and work towards. For this, as in 1995:

It will be critical for the international community to demonstrate a new commitment to the future - a commitment to inspiring a new generation of women and men to work together for a more just society. This new generation of leaders must accept and promote a world in which every child is free from injustice, oppression and inequality and free to develop her/his own potential (Paragraph 40).

A refrain that emerges from across the contributions to this IDS Bulletin is the need to close the implementation gap. UN Women note that 'progress towards substantive equality for women requires public action on three interrelated fronts: redressing socioeconomic disadvantage; addressing stereotyping, stigma and violence; and strengthening agency, voice and participation' (2015: 24). One thing we have learnt from the last 20 years is the power of social accountability as a force for demanding the fulfilment of obligations. As the SDGs come to shape the terrain of international development policy and funding, women's rights organisations and transnational networks have a hugely important role to play in monitoring implementation, holding states to account and mobilising consumer and political pressure on non-state actors, and contributing directly to the realisation of women's rights and empowerment by challenging limiting gender stereotypes and social norms, raising consciousness and promoting collective action. 
1 See, for example, www.takebackthetech.net.

\section{References}

Anderson, M. (2015) 'UK Aid Watchdog Criticises DfID over Partnerships with Private Sector', The Guardian, 21 May

Balakrishnan, R. and Elson, D. (2011) Economic Policy and Human Rights: Holding Governments to Account, London: Zed Books

Cornwall, A. (2014) Women's Empowerment: What Works and Why?, WIDER Working Paper WP/2014/104, Helsinki: UNU-WIDER

Cornwall, A.; Harrison, E. and Whitehead, A. (eds) (2007) 'Gender Myths and Feminist Fables: The Struggle for Interpretive Power in Gender and Development', Development and Change 38.1: 1-2

Eyben, R. and Turquet, L. (eds) (2013) Feminists in Development Organizations: Change from the Margins, Rugby: Practical Action

Htun, M. and Weldon, L. (2010) 'When do Governments Promote Women's Rights? A Framework for the Comparative Analysis of Sex Equality Policy', Perspectives on Politics 8.1: 207-16 Jolly, S.; Cornwall, A. and Hawkins, K. (eds) (2013) Women, Sexuality and the Political Power of Pleasure, London: Zed Books
Kabeer, N. (2012) Women's Economic Empowerment and Inclusive Growth: Labour Markets and Enterprise Development, SIG Working Paper 2012/1, London: International Development Research Centre/ Department for International Development Koffman, O. and Gill, R. (2014) 'I Matter and So Does She: Girl Power, (Post) Feminism and the Girl Effect', in D. Buckingham, S. Bragg and M.J. Kehily, Youth Cultures in the Age of Global Media, Basingstoke: Palgrave Macmillan

Mukhopadhyay, M. (2014) 'Mainstreaming Gender or Reconstituting the Mainstream? Gender Knowledge in Development', fournal of International Development 26.3: 356-67

Sholkamy, H. (2011) How can Social Protection Provide Social Justice for Women?, Pathways Policy Paper, October, Brighton: Pathways of Women's Empowerment

UN Women (2015) 'Transforming Economies, Realizing Rights', Progress of the World's Women 2015-2016, New York NY: UN Women

UN Women (2014) Report of the Expert Group Meeting on Envisioning Women's Rights in the Post-2015 Context, New York, 3-5 November 